\title{
Recent Advances in the Fluid Dynamics of Ladle Metallurgy
}

\author{
Gordon IRONS, ${ }^{1 / *}$ Anand SENGUTTUVAN ${ }^{1)}$ and Krishnakumar KRISHNAPISHARODY ${ }^{2)}$ \\ 1) Steel Research Centre, McMaster University, Hamilton, Canada 1280 Main Street West, Hamilton, Ontario, L8S 4L7 Canada. \\ 2) Saarstahl Innovation, D-66330, Völklingen, Germany.
}

(Based on Honorary Member Lecture; held at Tokyo Institute of Technology on March 21, 2014.

Manuscript received September 11, 2014.)

\begin{abstract}
Ladle or secondary metallurgy in steelmaking is an essential process step for the production of highquality steel. There has been a vast amount of research conducted in this area, particularly regarding refining reactions and inclusion chemistry. More recently, the fluid dynamic aspects of the process have been examined in more detail to provide better control of the process. In this Honorary Lecture two recent aspects related to fluid dynamics are reviewed; gas-liquid plumes and entrainment of slag droplets in metal.
\end{abstract}

KEY WORDS: modeling; steelmaking; ladle metallurgy; slag.

\section{Introduction}

Ladle or secondary steelmaking is the process step after primary steelmaking (BOF or EAF steelmaking) and before casting, so it is the final opportunity to modify the steel chemistry. Therefore, it is essential that the chemistry in terms of dissolved elements, and inclusion chemistry and size distribution be correct. During ladle processing, the steel melt is usually stirred by an inert gas such as Argon through porous plug(s) fitted in the bottom of the ladle or a lance inserted deep into the melt. The purging serves several purposes viz., homogenizing the melt, flotation of inclusions, enhancing the rates both of refining reactions and dissolution of alloying elements and promoting inter-phase interactions in the ladle.

There has been a large amount of work conducted on various aspects of the fluid dynamics of gas-metal-slag interactions relevant to ladle metallurgy. In this Honorary Lecture I have chosen to review two works in my group that provide some new insight into the industrial processes:

1. The first is a model of gas-liquid plumes that provides a relatively simple way to calculate the gas void fraction, gas-liquid plume area, and the gas and liquid velocities. The model is important because it shows that the modified Froude number, previously used for such studies is not relevant, but that a plume Froude number is the appropriate group for dynamic similarity. It also clarifies that the type and diameter of injector is largely irrelevant and that the gas-liquid density ratio is not important.

2. The second is a study, still underway, to determine the extent of entrainment of slag droplets into steel during gas stirring. This has been an unresolved issue for over 30 years, and this work is providing details of the important variables

* Corresponding author: E-mail: ironsga@mcmaster.ca DOI: http://dx.doi.org/10.2355/isijinternational.55.1 in this process.

\section{Gas-Liquid Plumes}

In Ladle Metallurgy, the flow rates are very low, so that the gas-liquid plume appears as in the water model in Fig. 1. In previous work by the present authors on the dynamics of two-phase plumes, ${ }^{1}$ it was proven that only two dimensionless quantities are required to characterize free-rising plumes as in ladle metallurgy applications. These are the non-dimensionalized gas flow rate $\left(Q^{*}\right)$ and axial height $\left(z^{*}\right)$, defined, respectively, as:

$$
\begin{gathered}
Q^{*}=\frac{Q}{g^{0.5} H^{2.5}} \\
z^{*}=\frac{z}{H}
\end{gathered}
$$

where $Q$ is the gas flow rate, $H$ is the metal height, $z$ is the

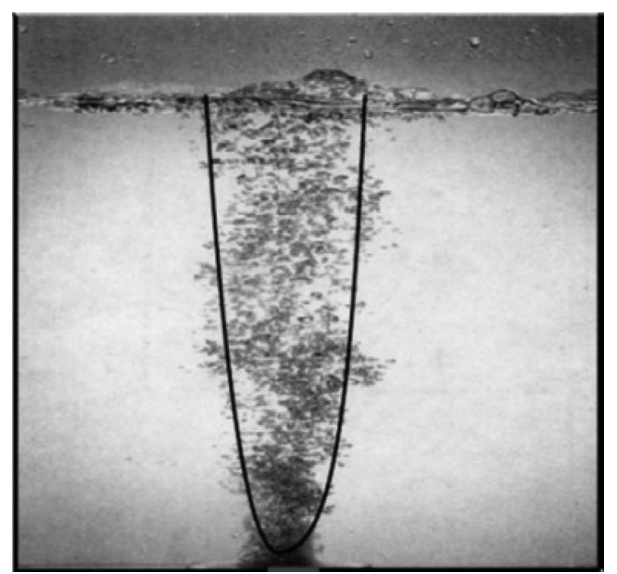

Fig. 1. Photograph of a water model of a gas-liquid plume, similar to ladle metallurgy stirring. 
vertical position and $g$ is the gravitational acceleration. It was also proven that the proper form of the Froude number relevant to Ladle Metallurgy is the plume Froude number, based on the liquid or plume velocity as the relevant velocity and the bath height as the characteristic dimension:

$$
F r_{P}=\frac{\bar{U}_{l}^{2}}{\bar{\alpha} g H}
$$

The plume Froude number arose from the non-dimensionalization of the equation for momentum in the free-rising part of the plume. In that study the plume Froude number was mathematically related to $\left.Q^{*}: 1\right)$

$$
F r_{P}=\Phi\left(Q^{*}, z^{*}\right)
$$

Therefore, dynamic similarity is achieved by matching either $F_{p}$ or $Q^{*}$ and $z^{*}$ in the plume. It is more convenient to use $Q^{*}$ because it contains variables that are set by the operator.

Further, by using the mathematical descriptions of twophase systems, viz., the well-known Eulerian-Lagrangian or bubble tracking models and momentum and continuity for the phases, a similarity framework was developed to correlate all the major plume parameters to $Q^{*}$ and $z^{*}$ on a fundamental basis. ${ }^{1)}$ In this framework, the similarity parameters for the void fraction, plume radius, liquid and gas velocities, respectively are:

$$
\begin{gathered}
\bar{\alpha}=1.13\left(Q^{*}\right)^{0.63}\left(z^{*}\right)^{-1.57} \ldots \ldots \\
R_{p}^{*}=\frac{R_{p}}{H}=0.65\left(Q^{*}\right)^{0.2}\left(z^{*}\right)^{0.5} \ldots \\
\bar{U}_{l}^{*}=\frac{\bar{U}_{l}}{\sqrt{g H}}=1.16\left(Q^{*}\right)^{0.32}\left(z^{*}\right)^{-0.28} \\
\bar{U}_{g}^{*}=\frac{\bar{U}_{g}}{\sqrt{g H}}=3.52\left(Q^{*}\right)^{0.37}\left(z^{*}\right)^{-0.43}
\end{gathered}
$$

where the overbar indicates that the quantity is averaged over the plume cross-section and the superscript * indicates that that the variable is non-dimensional.

The model was also extended to mixing times, $t_{m}$ (the time to achieve a particular degree of chemical homogeneity, $95 \%$ in this case) as a function of gas injection rate: ${ }^{2)}$
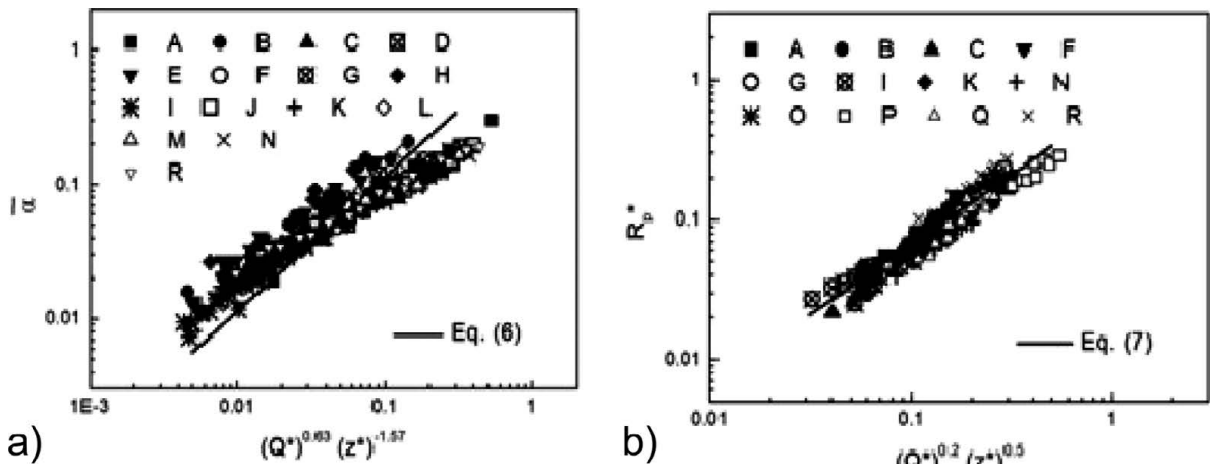

b)

$\left(Q^{*}\right)^{0.3}\left(z^{*}\right)^{0.5}$
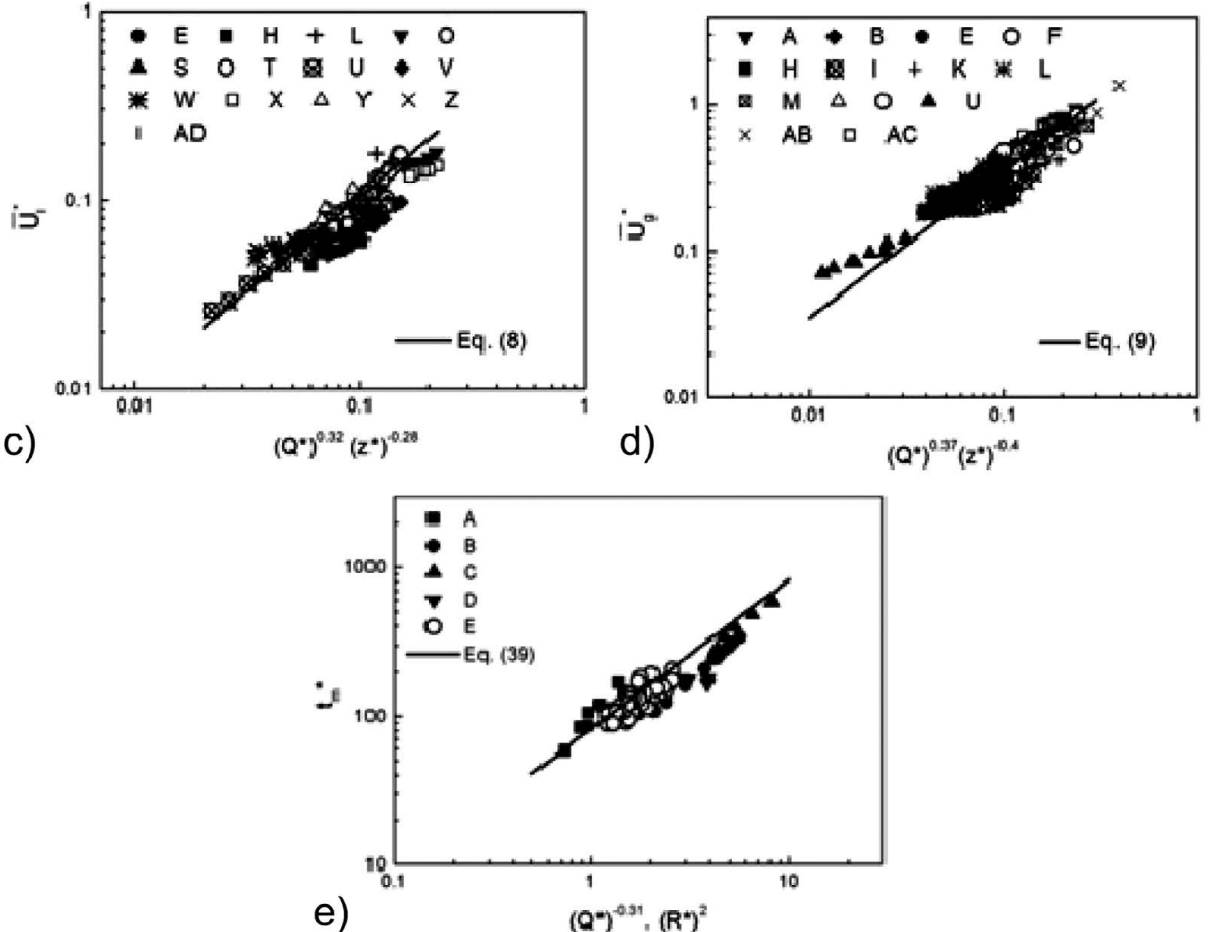

Fig. 2. Similarity representation of the plume void fraction (a), plume radius (b), liquid velocity (c), gas velocity (d) and mixing time (e). The letters in the figures refer to the source of the data, explained in the original Refs. 2) and 3). Equation (39) in Fig. 2(e) is Eq. (9) in this text. 


$$
t_{m}^{*}=t_{m} \sqrt{\frac{g}{H}}=82.4\left(Q^{*}\right)^{-0.31}\left(R^{*}\right)^{2}
$$

Where $R^{*}$ is the dimensionless vessel radius:

$$
R^{*}=\frac{R}{H}
$$

The equations in this model, Eqs. (5) to (9), have been compared with all available data in Fig. 2. Further details are contained in other references. $^{2,3)}$ It is clear that there is remarkably good agreement between the model and data over a wide range of conditions. It should also be noted that the model is entirely self-consistent which means that the variables scale properly, according to plume Froude number similarity. Refs. 2) and 3) further argue that because the modified Froude number (widely used in gas injection studies) and the specific energy input should not be used in ladle metallurgy applications because they do not conform to plume Froude number similarity.

\section{Entrainment of Slag Droplets into Steel}

The two-phase plume of gas and liquid steel that was described in the previous section rises to the surface, and creates a raised spout of steel that pushes the slag layer radially leaving an exposed metal portion known as an "open eye", as shown in Fig. 3. The relative motion between the slag and the outflowing metal causes instability in the slag metal interface and leads to droplet formation beyond a critical velocity, known as entrainment. Such an entrainment process leads to increased slag-metal interfacial area that in turn increases the interfacial mass transfer rates for refining reactions such as desulphurization, but could potentially lead to slag entrainment in the product.

There has been a substantial amount of work on the effect of entrainment on mass transfer in industrial trials and in water modelling. There is a sudden increase in mass transfer rate at a certain gas injection rate. ${ }^{4)}$ Since it is impossible to see in liquid metal systems, water modelling has been used to identify the critical gas flow rate to be at the onset of entrainment of upper phase into the lower. Currently, there is no quantitative link between the entrainment conditions in the system and the rate of refining. Many attempts have been made in the past to characterize this degree of entrainment, most of which are limited to finding the critical con-

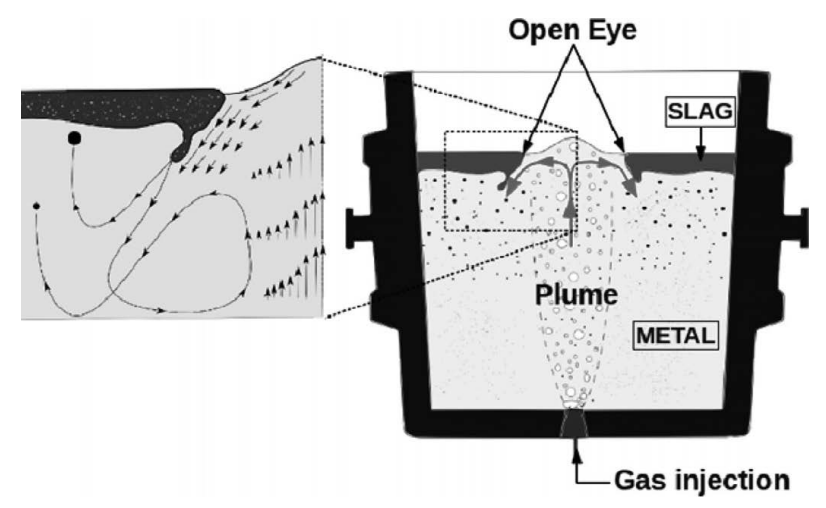

Fig. 3. Schematic of gas stirred ladle and flow features causing entrainment of slag into metal around the eye region. dition for onset of entrainment. ${ }^{5-9)}$ Despite such efforts, such models are not sufficiently tested due to the difficulty in measuring entrainment parameters even in aqueous models.

The purpose of the current work is to use multiphase computational fluid dynamics to simulate slag entrainment and obtain estimates for number and size of droplets formed so that the interfacial area for slag metal reaction rates can be calculated. The results from the present study will be used in a model under development to calculate mass transfer rates. The fluid flow equations are solved using the Large Eddy Simulation (LES) approach. However, since it is computationally very intensive to perform large eddy simulations for the entire ladle, only a thin slice of the ladle domain is considered, as shown in Fig. 4.

\subsection{Mathematical Model Description}

The multiphase large eddy simulations were carried out using Gerris Flow Solver, an Open source CFD package. ${ }^{10)}$ For a given boundary conditions viz. geometry of the domain, inlet and outlet conditions, Gerris calculates fluid flow in the domain by solving the incompressible NavierStokes equation with gravity and surface tension terms. By using the Volume of Fluid method, it tracks the interface between two immiscible phases. The governing equations are as follows:

Momentum conservation:

$$
\rho_{m}\left(\frac{\partial \vec{U}}{\partial t}+\vec{U} \cdot \nabla \vec{U}\right)=-\nabla P+\nabla \cdot\left(\mu_{m} \nabla \vec{U}\right)+\vec{g}+\sigma \kappa \delta \vec{n}
$$

where, $\vec{U}$ is the velocity field to be obtained, $\rho_{m}$ and $\mu_{m}$ are the mixture density and viscosity respectively, $\vec{g}$ is gravitational acceleration, $\sigma$ is the surface tension coefficient, $\kappa$ is the radius of curvature, $\delta$ is the Kronecker delta which is unity at the interface, otherwise zero, and $\vec{n}$ is the unit normal vector to the two fluid interface.

Incompressibility condition:

$$
\frac{\partial \vec{U}}{\partial t}+\nabla \cdot \vec{U}=0
$$

VOF advection equation:

$$
\frac{\partial F}{\partial t}+\vec{U} \cdot \nabla F=0
$$

where $F$ is the volume fraction field defined as 1 for upper phase, 0 for lower phase and for interface between 0 and 1 .

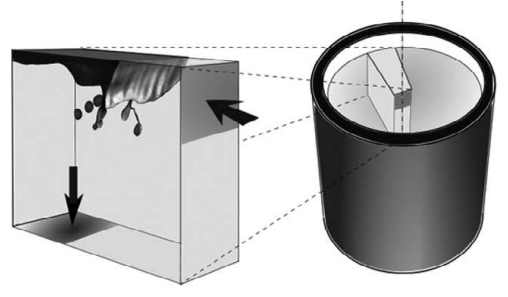

(a)

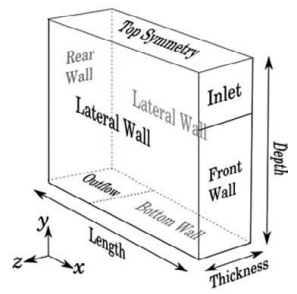

(b)
Fig. 4. (a) Schematic of thin slice of fluid domain in the ladle, considered for the Large Eddy Simulations. (b) Nomenclature of various boundaries of the LES domain. 
Gerris does not have any turbulence model; it was implemented by the present authors; further details are elsewhere. $^{11)}$

In Gerris, the grid is generated automatically, although based on user defined criteria, into quadtree (in 2D) or octree (in 3D) discretization that can be adaptively refined based on user criteria. As a result, for multiphase problems like entrainment that involves wide range of spatial scales, the total number of grid points can be decreased by an order of magnitude by adaptively refining only at the interface between two phases. The adaptation can be performed every time step with little computational overhead $(<5 \%)$. Another feature in Gerris is that by coupling the so called 'balanceforce continuum-surface-force surface-tension' method and the height function method to estimate interface curvature, it has been possible to achieve exact balance between surface tension and pressure gradient. This assures better representation of interfaces than offered by many other flow solvers. Since the phenomena are not wall dominated, no wall treatment was applied to the LES model.

The location of the inlet and the outflow planes are marked in Fig. 4(b). The height of the inlet was always set to the slag thickness. The inlet condition for the LES is the velocity field at the location of the inlet plane in the ladle. It is unnecessary and prohibitively expensive to perform LES on the whole ladle; however, the proper turbulent conditions need to be specified at the inlet plane. These conditions were extracted from a Reynolds-Averaged Navier-Stokes (RANS) simulation for the entire ladle, as they are relatively inexpensive. These computations are called the "precursor RANS simulations". Still, the timeaveraged velocity field obtained from a RANS simulation is insufficient, as an appropriate inlet condition should also have the fluctuating components that are characteristic of turbulence. The fluctuating components were 'synthesized' by employing the 'Synthetic Eddy Method' (SEM) of Jarrin et al. $^{12)}$ as described elsewhere. ${ }^{11)}$

\subsection{Cases Simulated}

All ladle operating parameters for the simulations correspond to a ladle of $2 \mathrm{~m}$ diameter, steel bath height of $2 \mathrm{~m}$ at a melt temperature of $1600^{\circ} \mathrm{C}$. The nominal slag thickness was taken to be $0.1 \mathrm{~m}$ to give a slag to steel height ratio of $1 / 20$. A thin slice of thickness $0.1 \mathrm{~m}$ was considered for the LES domain. The length and the depth of the domain were $0.6 \mathrm{~m}$, sufficiently large to avoid wall effects and to also prevent droplets being drained down the outflow, before being counted. The height of the inlet was the same as the thickness of slag and therefore varied with the slag thickness. Three specific gas injection rates were chosen based on the industrial range, 2, 4 and 8 standard litres per minute per ton (slpm/ton) of steel that gives 355, 710 and $1421 \mathrm{lpm}$ at half bath height and $1600^{\circ} \mathrm{C}$. Here $4 \mathrm{slpm} /$ ton is the base case value and the others obtained by halving and doubling the base value. Three slag viscosities were considered, again by halving and doubling the base case value of 0.11 Pa.s. This value was calculated using the National Physical Laboratory model for slag of $40 \% \quad \mathrm{Al}_{2} \mathrm{O}_{3}-40 \%$ $\mathrm{CaO}-10 \% \mathrm{SiO}_{2}-10 \% \mathrm{MgO}$, a typical composition of ladle desulphurization slags. ${ }^{13)} \mathrm{A}$ value of $0.22 \mathrm{~Pa} . \mathrm{s}$ corresponds to a slag of $30 \% \mathrm{Al}_{2} \mathrm{O}_{3}-50 \% \mathrm{CaO}-10 \% \mathrm{SiO}_{2}-10 \% \mathrm{MgO}$ that
Table 1. Summary of simulation parameters that are dependent on gas injection rate.

\begin{tabular}{lccc}
\hline Specific Gas Injection Rate, (STP)lpm/ton & 2 & 4 & 8 \\
\hline Gas Injection Rate at half bath height, lpm & 355 & 710 & 1421 \\
Radius of Slag Eye, m & 0.34 & 0.45 & 0.60 \\
Slag Thickness during operation, cm & 11.3 & 12.5 & 15.4 \\
\hline
\end{tabular}

Table 2. List of cases of simulations performed. The table has three, 3-by-3 matrices of cases, one for each gas injection rate; the moderate gas injection rate has all possible cases, whereas the other matrices have only the diagonal cases.

\begin{tabular}{c|ccc|ccc|ccc}
\hline$Q, \mathrm{lpm} / \mathrm{ton}$ & \multicolumn{3}{|c|}{2} & \multicolumn{3}{|c|}{4} & \multicolumn{3}{|c}{8} \\
\hline$\sigma, \mathrm{N} / \mathrm{m} \rightarrow$ & 0.25 & 0.5 & 1.0 & 0.25 & 0.5 & 1.0 & 0.25 & 0.5 & 1.0 \\
\hline$\mu, \mathrm{Pa} . \mathrm{s} \downarrow$ & & & & & & & & & \\
0.055 & 10 & & & 1 & 2 & 3 & 13 & & \\
0.11 & & 11 & & 4 & 5 & 6 & & 14 & \\
0.22 & & & 12 & 7 & 8 & 9 & & & 15 \\
\hline
\end{tabular}

is close to lime saturation. Although there is no specific data on interfacial tension for this slag, various studies for different slag-metal combinations have shown that equilibrium interfacial tension values vary somewhere between 0.6 and $1.4 \mathrm{~N} / \mathrm{m}^{14-16)}$ Moreover, Gaye et al. $^{14)}$ have shown that a high flux of oxygen atoms transferred across the interface could drop the interfacial tension to virtually zero. Considering these facts, a low value of $0.5 \mathrm{~N} / \mathrm{m}$ was taken to be the base case and two others were obtained by halving and doubling this value. The density of the slag was taken to be $2800 \mathrm{~kg} / \mathrm{m}^{3}$. Table 1 summarizes the ladle conditions that are flow rate dependent.

To study the role of viscosity and interfacial tension, separately, 9 simulations were performed at moderate gas injection rate of $4 \mathrm{lpm} / \mathrm{ton}$. At the other two gas injection rates, 3 simulations were performed for each, by simultaneously increasing the slag viscosity and the interfacial tension. In all these simulations, slag thickness was taken to be the nominal thickness of $0.1 \mathrm{~m}$. However during ladle operation, when the slag eye forms and its size increases with gas injection rate, the slag thickness also increases. The values calculated based on volume continuity are summarised in Table 1. So 9 more cases that are along the diagonals of sub matrices in Table 2, were performed for slag thicknesses that vary with gas injection rate.

\subsection{LES Results}

This section discusses the results of simulations including only droplets of diameter greater than $4 \mathrm{~mm}$. Various features of deformation of the slag metal interface are shown in Fig. 5 in two views of same snapshot of simulation for Case-13.

Entrainment Rate is defined as the number of slag droplets entrained per second. Figures 6(a) and 6(b) show the variation of entrainment rate with slag-metal interfacial tension and slag viscosity at gas injection rate of $4 \mathrm{lpm} /$ ton and slag thickness of $0.1 \mathrm{~m}$. An increase of either of the fluid properties decreases the entrainment rate, although interfacial tension has more effect than the slag viscosity. So the 


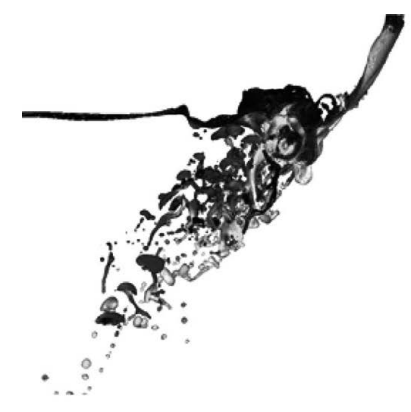

(a)

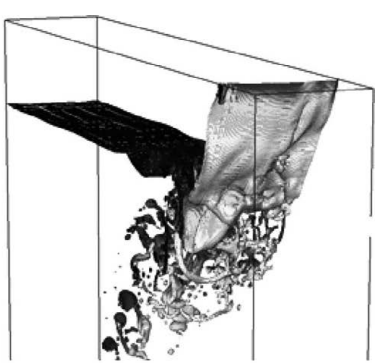

(b)
Fig. 5. (a) Side view and (b) perspective view of slag-metal interface in a same simulation snapshot, showing various interface deformation features like waves, ligaments and droplets.

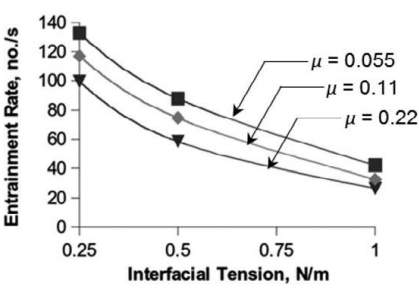

(a)

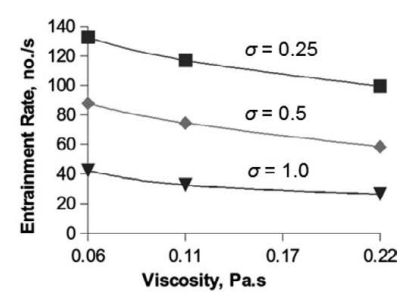

(b)
Fig. 6. (a) Plots of entrainment rate versus slag-metal interfacial tension for various slag viscosities at $Q=4 \mathrm{lpm} /$ ton and $h_{U}=$ $0.1 \mathrm{~m}$. (b) Same values of entrainment rate as in (a) replotted against slag viscosity for various interfacial tension values.

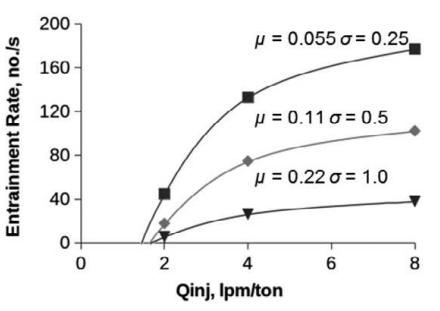

(a)

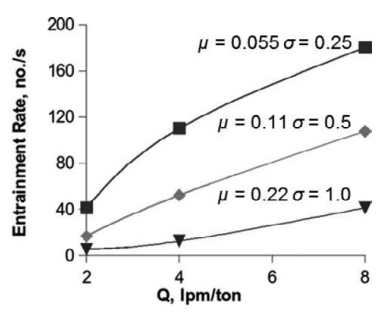

(b)
Fig. 7. Entrainment versus gas injection rate for simulation cases with (a) constant slag thickness (b) slag thickness that vary with gas injection rate.

resistance to entrainment is a function of both interfacial tension and slag viscosity.

The results of the cases in the diagonal of the sub-matrices in Table 2, are plotted in Figs. 7(a) and 7(b). Figure 7(a) contains the results of simulations for the constant slag thickness and Fig. 7(b) contains the results of simulations with slag thicknesses that vary with gas injection rate. The cases with constant slag thickness exhibit an asymptotic increase of entrainment rate with gas injection rate, for various fluid properties. These cases do not fully include the effect of gas injection rate due to their constant slag thickness, but are good to study the effect of flow velocity near the slag-metal interface. On the other hand the cases with variable slag thickness show ever increasing entrainment rate.

The average velocity of steel flow near the slag metal interface was calculated by volume averaging the norm of

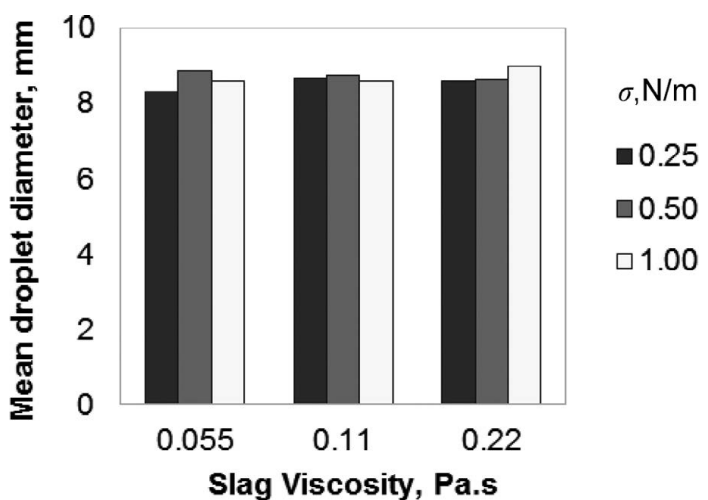

Fig. 8. Sauter mean droplet diameter for various slag viscosity and slag metal interfacial tension $(\sigma)$.

velocity from a very large number of node points $(\sim 105)$. Repeating the procedure at various time steps and taking the average of these, the average bulk velocity of liquid steel near the slag metal interface was calculated. An interesting feature in Fig. 7(a) is the convergence of all the curves to a point where entrainment rate is zero for a finite gas injection rate.Fitting of first order exponential decay to the curves in Fig. 7(a) yields flow rates of 1.44 to $1.65 \mathrm{slpm} /$ ton. From the simulation results the steel velocity for such cases is 0.50 to $0.52 \mathrm{~m} / \mathrm{s}$; further details have been previously presented. ${ }^{11)}$ These values are close to the value of $0.5 \mathrm{~m} / \mathrm{s}$ estimated by Krishnapisharody and Irons ${ }^{17)}$ using their model based on Kelvin-Helmholtz instability criterion for the onset of entrainment, although for a very thin slag of $3.0 \mathrm{~cm}$ thickness.

The Sauter mean diameter $\left(D_{32}\right)$ estimated from a particle size distribution with discrete size classes is defined as, ${ }^{18)}$

$$
D_{32}=\frac{\sum\left(f D^{3}\right)}{\sum\left(f D^{2}\right)},
$$

where $f$ is the distribution frequency and $D$ is the particle diameter. This averaging was chosen because the particle with the Sauter mean diameter will have the same ratio of volume to surface area as the entire ensemble of droplets, ${ }^{18)}$ which is very relevant to the role of entrainment in slag metal interfacial mass transfer. The Sauter mean diameter calculated for the cases 1 to 9 in Table 2 are plotted as histogram in Fig. 8; these cases have constant gas injection rate but varying fluid properties. The absence of any systematic difference among these cases indicates that slag viscosity and slag-metal interfacial tension do not significantly affect the droplet sizes.

\subsection{Discussion}

To the authors' knowledge this is the first time in ladle metallurgy a high resolution simulation was performed for slag entrainment by applying relevant fluid flow conditions existing in a full scale gas stirred ladle. This was possible due to the adaptive refinement feature and the accurate surface tension model of Gerris and the ability to generate turbulent inlet conditions using the synthetic eddy method. Furthermore, the present approach was compared with droplet break-up in a water model of the slag-metal interface ${ }^{17)}$ and found to be in reasonable agreement. Unfortunately, it 
would be very difficult to validate the present work against real slag-metal systems due to the difficulty in making such measurements.

The present work provides some insight into the important variable influencing the creation of slag droplets which in a qualitative sense has been linked to increased rates of mass transfer. ${ }^{4)}$ As discussed earlier, Fig. 7(a) shows that the onset of droplet formation velocities are consistent with the KelvinHelmholtz instability as Krishnapisharody ${ }^{17)}$ found in water models and simple VOF codes. The computational results demonstrate that the entrainment rate is very sensitive to the interfacial tension between slag and metal, compared to slag viscosity. This is a completely new finding.

\section{Conclusions}

This paper is a brief review of some of the work that highlights the importance of fluid dynamic phenomena in ladle metallurgy. The plume dynamics are dominated by balance between the buoyancy of the plume and inertia of the liquid; thus, ladle Froude number similarity is achieved. For these phenomena, interfacial phenomena at the injector inlet or at the gas-liquid interfaces are of secondary importance. However, for the issues related to slag-metal interactions, the physical properties of the slag, particularly, the interfacial tension, are of prime importance. These issues are very difficult to investigate in full-scale systems, so the present approach with computational fluid dynamics may continue to improve our understanding of these phenomena. It is also clear that our understanding of these phenomena is far from complete, and that with better understanding we may be able to improve ladle metallurgy processes.

\section{REFERENCES}

1) K. Krishnapisharody and G. A. Irons: ISIJ Int., 50 (2010), 1413.

2) K. Krishnapisharody and G. A. Irons: Materials Processing Towards Properties, Seetharaman Seminar, Jernkontoret, Stockholm, (2010), 317.

3) K. Krishnapisharody and G. A. Irons: Metall. Mater. Trans. B, 44B (2013), 1486.

4) J. Ishida, K. Yamaguchi, S. Sugiura, K. Yamano, S. Hayakawa and N. Demukai: Denki-Seiko (Electric Furnace Steel), 52 (1981), 2 (Cited in S. Asai, I. Muchi and M. Kawachi, Fluid Flow and Mass Transfer in Gas Stirred Ladles, Foundry Processes, Their Physics and Chemistry, Plenum Press, New York, (1988), 261).

5) J. Mietz, S. Schneider and F. Oeters: Steel Res., 62 (1991), 10.

6) S-H. Kim, R. J. Fruehan and R. I. L. Guthrie: Steelmaking Conf. Proc., Iron and Steel Society, Warrendale, PA, (1987), 107.

7) M. Iguchi, Y. Sumida, R. Okada and Z. Morita: ISIJ Int., 34 (1994), 164.

8) K. Krishnapisharody and G. A. Irons: EPD Congress 2008, The Mineral, Metals and Material Society, Warrendale, PA, (2008), 293.

9) J. Mietz, S. Schneider and F. Oeters: Steel Res., 62 (1991), 1.

10) Gerris Flow Solver, http://gfs.sourceforge.net/wiki/index.php/Main Page, (accessed 2014-01-10)

11) A. Senguttuvan and G. Irons: AISTech 2014 Proc., Association of Iron and Steel Technology, Warrendale, PA, (2014), 1453.

12) N. Jarrin, R. Prosser, J.-C. Uribe, S. Benhamadouche and D. Laurence: Int. J. Heat Fluid Flow, 30 (2009), 435.

13) J. Ekengard, A. M. T. Andersson and P. G. Jonsson: Ironmaking Steelmaking, 35 (2008), 575.

14) H. Gaye, L. D. Lucas, M. Olette and P. V. Riboud: Can. Metall. Q., 23 (1984), 179.

15) I. Jimbo, Y. Chung and A. W. Cramb: ISIJ Int., 36 (1996), S42.

16) S. C. Park, H. Gaye and H. G. Lee: Ironmaking Steelmaking, 36 (2009), 3.

17) K. Krishnapisharody: PhD Thesis, McMaster University, Hamilton, Canada, (2006).

18) Sauter Mean Diameter, http://www.thermopedia.com/content/1108/, (accessed 2014-01-10). 